\title{
Identifikasi Molekuler Blastocystis sp. pada Monyet Ekor Panjang (Macaca fascicularis) di Taman Nasional Baluran, Situbondo, Jawa Timur
}

\author{
Molecular Identification of Blastocystis sp. in Long-Tailed Macaque (Macaca fascicularis) \\ at Baluran National Park, Situbondo, East Java
}

\author{
Dyah Ayu Kurniawati ${ }^{1}$, Lucia Tri Suwanti ${ }^{2,3 *}$, Nunuk Dyah Retno Lastuti ${ }^{2}$, Setiawan \\ Koesdarto $^{2}$, Endang Suprihati ${ }^{2}$, Mufasirin ${ }^{2,3}$, Arif Pratiwi ${ }^{4}$ \\ ${ }^{1}$ Mahasiswa Magister Universitas Airlangga, Surabaya, Indonesia, ${ }^{2}$ Departemen Parasitologi Veteriner, \\ Universitas Airlangga, Surabaya, Indonesia, ${ }^{3}$ Lembaga Penyakit Tropis, Universitas Airlangga, Surabaya, \\ Indonesia; ${ }^{4}$ Taman Nasional Baluran, Situbondo, Indonesia \\ *Corresponding author: tswant@gmail.com
}

\begin{abstract}
Abstrak
Interaksi yang dekat antara monyet ekor panjang dengan manusia dapat meningkatkan risiko penularan penyakit zoonosis. Blastocystis $s p$. adalah protozoa gastrointestinal pada manusia dan hewan yang yang bersifat zoonosis. Penelitian ini bertujuan untuk mengidentifikasi Blastocystis sp. yang menginfeksi monyet ekor panjang melalui identifikasi molekuler. Identifikasi Blastocystis sp. pada penelitian ini menggunakan metode morfologis dan molekuler. Sebanyak 90 feses individu monyet ekor panjang Taman Nasional Baluran dilakukan pemeriksaan secara mikroskopis setelah dilakukan kultur pada Jones Medium. 28 dari sampel yang positif secara mikroskopis dilanjutkan dengan uji PCR dengan target primer barcode region yang mempunyai visualisasi 600bp. Tiga sampel dengan band positif 600bp dilanjutkan dengan squencing. Hasil sekuens diproses dalam BLAST dan MLST. Satu sampel yang terkonfirmasi sebagai Blastocystis sp. dengan infeksi campuran dari subtipe 1 alel 2 dan subtipe 3 alel 34. Hasil menunjukkan bahwa Blastocystis sp. terdapat pada monyet ekor panjang di Taman Nasional Baluran dengan prevalensi rendah.
\end{abstract}

Kata kunci: Blastocystis sp., monyet ekor panjang, Taman Nasional Baluran, penyakit zoonosis

\begin{abstract}
The close contact between macaque and humans can increase the risk of disease transmissions. Blastocystis sp. is a gastrointestinal protozoa in human and animal which considered zoonotic. This study aimed to identify Blastocystis sp. infecting macaque with molecular identification. To provide identification about Blastocystis sp., we adopted both morphologic and molecular methods. We collected 90 unidentified individuals of long tailed macaque in Baluran National Park and did microscopic screening after culture in Jones Medium. A total of 28 from positive microscopic samples were used in polymerase chain reaction targeting barcode region with visualization of $600 \mathrm{bp}$. Three samples with positive band 600bp continued sequencing. The result processed in BLAST and MLST. One sample confirmed as Blastocystis sp. with mix infection of subtype 1 allele 2 and subtype 3 allele 34. The results indicate that Blastocystis sp. existed in macaques in Baluran National Park with low prevalence.
\end{abstract}

Keywords: Blastocystis sp., long-tailed Macaque, Baluran National Park, zoonotic disease

Received: 29 Januari 2020

Revised: 13 Maret 2020

Accepted: 17 April 2020

\section{PENDAHULUAN}

Interaksi antara manusia dan monyet ekor panjang telah dilaporkan terjadi sejak satu dekade yang lalu di Taman Nasional Baluran (TN Baluran). Interaksi ini timbul disebabkan oleh pemberian pakan oleh pengunjung yang masif sehingga terjadi perubahan tingkah laku monyet ekor panjang yang pada mulanya takut dengan manusia menjadi agresif dan berani. Kejadian ini menyebabkan resiko transmisi penyakit antara monyet ekor panjang dan manusia semakin tinggi (Friishansen et al., 2015). 
Blastocystis sp. merupakan salah satu protozoa gastrointestinal yang umum ditemukan pada manusia dan hewan termasuk Non Human Primate (NHP) dan berpotensi zoonosis (Parkar., 2015). Blastocystis sp. merupakan salah satu agen penyebab gangguan gastrointestinal seperti Irritation Bowel Syndrome, diarrhea dan gangguan gastrointestinal yang lain (Stensvold, 2013). Transmisi Blastocystis sp. di alam terjadi melalui rute fekal oral. Transmisi dari NHP ke manusia telah dilaporkan pada beberapa penelitian secara molekuler (Stensvold, 2013).

Alfellani et al. (2013) melaporkan Blastocystis sp. ditemukan dalam feses penjaga NHP di kebun binatang. Yoshikawa et al. (2009) mengidentifikasi bahwa Blastocystis sp. dengan subtipe yang sama ditemukan pada anak-anak dan monyet rhesus di satu area di Khatmandu India. Studi telah menunjukkan bahwa terdapat subtipe yang sama antara manusia dan NHP, adapun ST1, ST2, ST3, dan ST4 yang mendominasi (Yoshikawa et al., 2009; Alfellani et al., 2013; Ramírez et al., 2016). Meskipun terdapat laporan tersebut, sebagian besar kejadian zoonosis atau antroponotik tetap tidak diketahui dan harus dilakukan penelitian lanjut.

Tujuan penelitian ini adalah untuk mengetahui adanya infeksi Blastocystis sp. pada monyet ekor panjang di TN Baluran. Penelitian ini menggunakan metode molekuler dengan primer barcode region BhRDr dan RD5 (Scicluna et al., 2006) untuk identifikasi. Primer barcode region digunakan karena dapat mengidentifikasi subtipe dan alel Blastocystis sp.

\section{METODE PENELITIAN}

\section{Uji Kelayakan Etik}

Penelitian ini telah disetujui oleh TN Baluran Nomor SI.794/T.37/TU/KSA.6/9/2018 dan IACUC dengan izin etik No. 2.KE.001.01.2019 di bawah bimbingan Komisi Izin Etik Fakultas Kedokteran Hewan, Universitas Airlangga.

\section{Koleksi Sampel dan Kultur}

Sampel feses diambil dari 90 individu monyet ekor panjang di TN Baluran. Feses dikumpulkan dari zona Bekol dan Bama dimana terdapat interaksi tertinggi dari manusia dan monyet ekor panjang. Sampel dikumpulkan dari kotoran segar $(<12$ jam). Sampel feses dikumpulkan secara oportunistik dan non invasif dari tanah, segera setelah feses didefekasikan. Pengumpulan sampel dilakukan selama AgustusSeptember 2019. Sebanyak 2-4gram sampel di kultur dalam 12-15 ml Jones Medium dan dimasukkan dalam inkubator $37^{\circ} \mathrm{C}$. Pemeriksaan adanya Blastocystis sp. secara mikroskopis dilakukan pada 24, 48 dan 72 jam. Sampel positif akan diteruskan dengan uji molecular (Clark and Stensvold, 2016).

\section{Pemeriksaan dengan Metode Molekuler}

Sampel yang telah diobservasi dari pembiakan dan positif Blastocystis sp. dilakukan tahap identifikasi molekuler. Ekstraksi menggunakan gSYNCTM DNA Extraction Kit (Geneaid, Taiwan). Verifikasi sampel dilakukan dengan menggunakan primer spesifik barcode region BhRDr (5, GAGCTTTTTAACTGCAACAACG $3^{\circ}$ ) dan RD5 (5' ATCTGGTTGATCCTGCCAGT 3') dengan yang menghasilkan band $600 \mathrm{bp}$, adapun amplifikasi yang digunakan adalah 35 siklus dengan predenaturasi $94^{\circ} \mathrm{C}$ selama 1 menit, denaturasi pada $94^{\circ} \mathrm{C}$ selama 1 menit, annealing pada $59^{\circ} \mathrm{C}$ untuk 1 menit dan elongasi di $72^{\circ} \mathrm{C}$ selama 1 menit dan final ekstensi $72^{\circ} \mathrm{C}$ selama 2 menit (Scicluna et al., 2006). Sampel dinyatakan teridentifikasi Blastocystis sp. apabila hasil elektroforesis didapatkan pita dengan panjang 600 bp. Produk hasil PCR yang positif dilakukan sekuensing.

\section{Analisis data}

Data hasil sekuensing dari sampel yang didapat akan diolah dalam BLAST NCBI Genbank database dan diteruskan dengan Blastocystis Subtype (18S) Sequence Typing (MLST) databases untuk mengetahui alel.

\section{HASIL DAN PEMBAHASAN}

Prevalensi Blastocystis sp. pada monyet ekor panjang di TN Baluran berdasarkan pemeriksaan 
mikroskopik setelah dilakukan kultur sebesar $28 \%$ (25/90). Sampel yang positif ditemukan Blastocystis sp. pada stadium vakuolar, granular dan kista. Ukuran stadium vakuolar yang ditemukan berkisar antara 3.4-13.46 $\mu \mathrm{m}$ stadium granular yang ditemukan berkisar pada 9.64-16.6 $\mu \mathrm{m}$, sedangkan stadium kista yang ditemukan memiliki ukuran yang berkisar pada $30 \mu \mathrm{m}$. Hasil ini serupa dalam laporan dari Parija dan Jeremiah (2013) yang mengatakan bahwa ukuran Blastocystis sp. stadium vakuolar berkisar antara 3-120 $\mu \mathrm{m}$ sedangkan stadium granular rata-rata berukuran 15-25 $\mu \mathrm{m}$ (terbesar $80 \mu \mathrm{m}$ ) pada manusia. Zhang et al. (2012) juga melaporkan bahwa ukuran rata-rata stadium vakuolar antara 4-15 $\mu \mathrm{m}$ (Gambar 1).

Sebanyak 25 sampel dengan hasil positif secara mikroskopik dilanjutkan dengan uji secara molekuler. Uji molekuler menghasilkan tiga sampel positif yang ditandai dengan munculnya band 600bp (Gambar 2). Ketiga sampel dilakukan sekuensing. Hasil sekuensing di BLAST dalam NCBI Genbank database dan diteruskan dengan Blastocystis Subtype (18S) Sequence Typing (MLST) Databases untuk mengetahui dan menemtukan alel. Hasil dari BLAST dalam NCBI didapatkan Blastocystis sp. ST 1 dan ST 3, sedangkan hasil blasting pada MLST memperkuat dengan ditemukannya alel 2 pada Blastocystis sp. ST 1 dan alel 34 pada Blastocystis sp. ST 3.

Prevalensi Blastocystis sp. pada monyet ekor panjang di TN Baluran baik secara mikroskopik dan molekuler termasuk rendah. Penelitian yang sama dilakukan oleh Visusuk et al. (2017) di Thailand melaporkan bahwa prevalensi Blastocystis sp. pada monyet ekor panjang sebesar 24.5\%. Penelitian yang dilakukan Valenca-barbosa et al. (2019) di Rio de janeiro Brasil pada NHP menunjukkan prevalensi Blastocystis sp. sebesar 37\%. Laporan prevalensi Blastocystis $s p$. pada old world monkey dan new world monkey yang lakukan oleh Alfelani et al. (2013) menunjukkan tingkat prevalensi sebesar $66.9 \%$. Nilai prevalesi Blastocystis sp. tertinggi pernah dilaporkan oleh Zanzani et al. (2016) dari penangkaran monyet di China yaitu sebesar $87.6 \%$.
Vaisusuk et al. (2017) mengatakan rendahnya prevalensi yang ditemukan tersebut dapat disebabkan penyimpanan sampel (keterlambatan waktu sampling sampai analisis sampel). Selain itu perlu diketahui bahwa shedding Blastocystis sp. dalam feses adalah periodik (Clark dan Stensvold, 2016), hal ini juga terjadi dengan parasit gastrointestinal yang lain, sehingga dimungkinkan rendahnya prevalensi bukan berarti tidak adanya organisme pada host. Selain itu, penelitian dengan data prevalensi yang lebih tinggi sebagian besar dilaporkan dari NHP exsitu seperti kebun binatang, pusat rehabilitasi maupun penangkaran, dimana tingkat infeksi dan transmisi dimungkinkan lebih tinggi. Penelitian Blastocystis sp. pada monyet ekor panjang ataupun NHP yang hidup secara liar belum banyak dilakukan. Penelitian yang fokus meneliti Blastocystis sp. pada NHP liar dalam hal ini monyet ekor panjang hanya dilakukan oleh Vaisusuk et al. (2017). Adrus et al. (2019) melakukan penelitian tentang parasit gastrointestinal pada NHP liar di Malaysia, pada penelitian tersebut prevalensi Blastocystis sp. yang ditemukan hanya sebesar $2.5 \%$. Kedua penelitian tersebut melaporkan prevalensi rendah dari Blastocystis sp. pada NHP di alam liar. Adapun data di lapangan tentang penelitian serupa masih kurang. Rendahnya prevalensi dapat terjadi juga dikarenakan pengaruh pengambilan waktu sampling. Penelitian ini dilakukan pada musim kemarau dimana diduga menjadi salah satu penyebab prevalensi yang rendah. Satwa primata yang berada di habitat yang lebih lembap cenderung lebih berisiko terinfeksi parasit daripada area yang kering (Stuart et al., 1993). Penelitian yang dilakukan Siwila et al., (2011) melaporkan apabila musim penghujan mempunyai tingkat isidensi yang lebih tinggi dibanding musim kemarau terkait dengan kejadian infeksi protozoa saluran gastrointestinal.

Dua dari tiga sampel dengan hasil positif amplifikasi PCR menunjukkan organisme jamur setelah proses sekuensing, hal ini dikarenakan primer BhRDr dan RD5 bukan merupakan primer spesifik untuk Blastocystis namun juga 

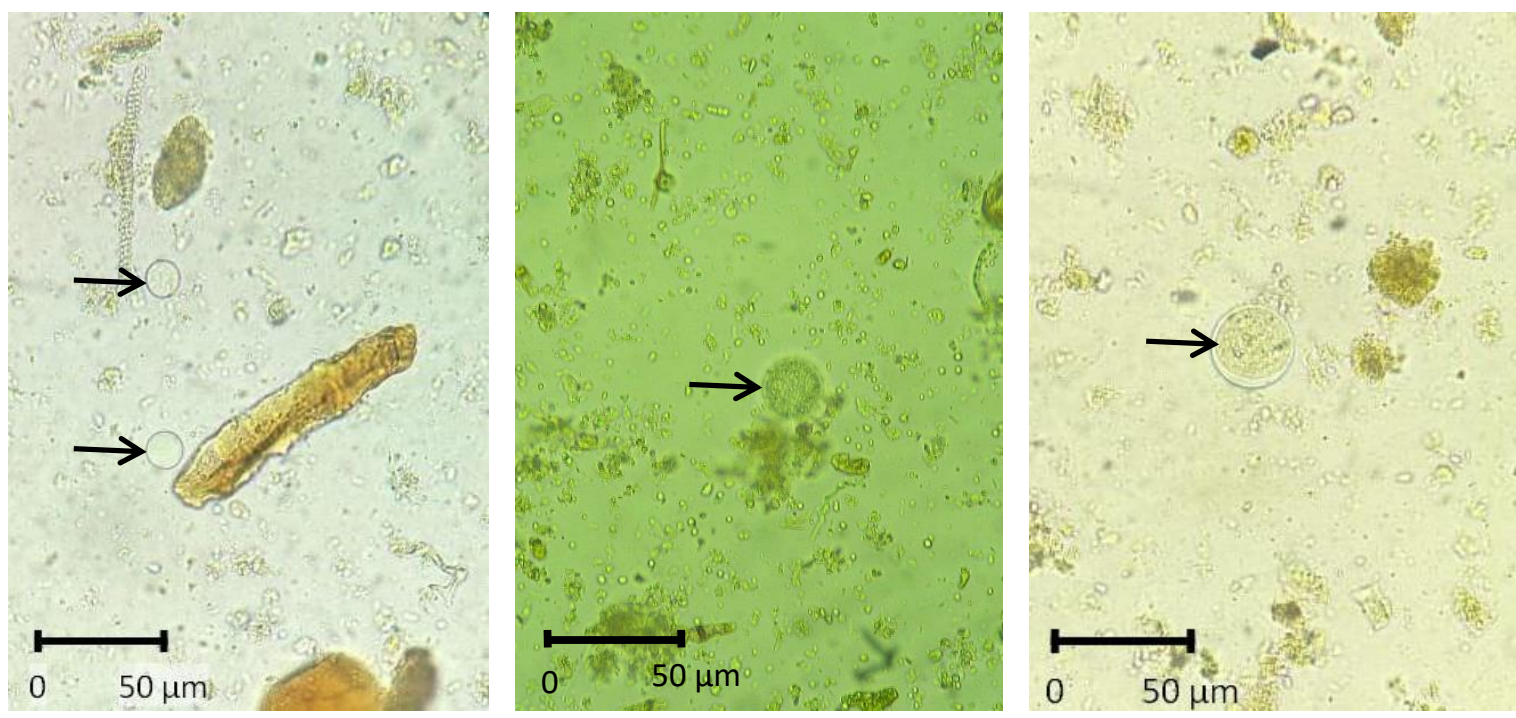

Gambar 1. Fase Blastocystis sp. yang ditemukan pada media kultur.

(a) Vakuolar (b) Granular (c) Kista

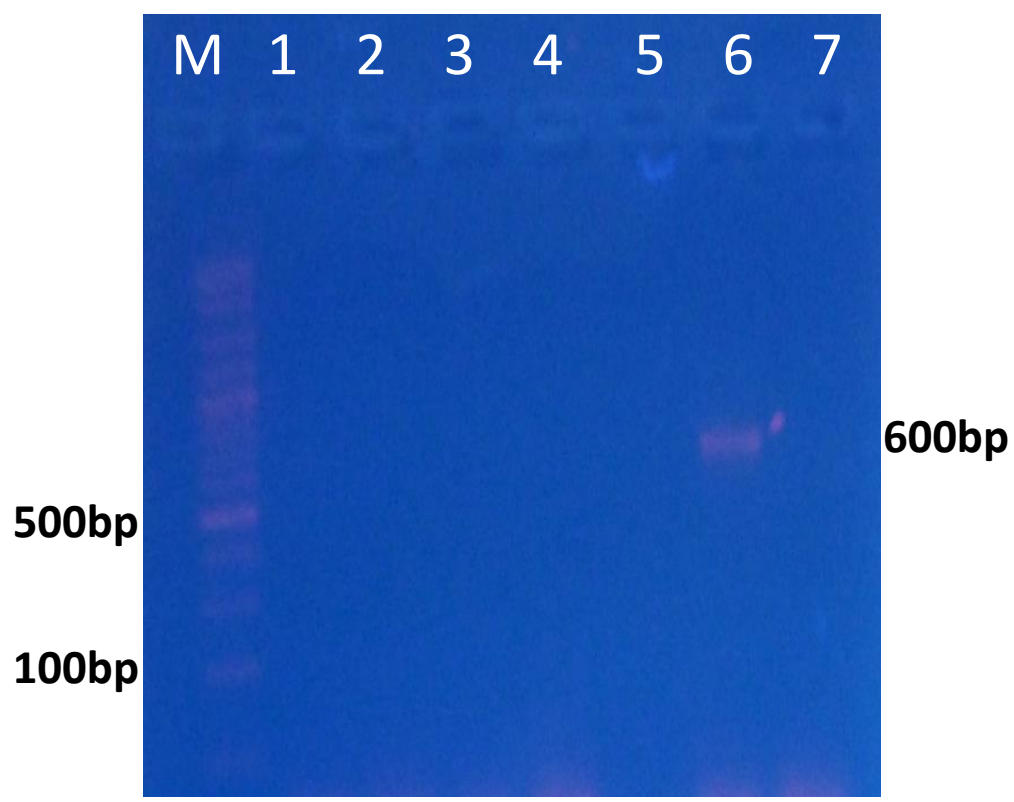

Gambar 2. Hasil visualisasi produk PCR RD5 dan BhRDr dengan menggunakan elektroforesis pada gel agarose $1.5 \%$; M: marker; sampel 6=BK6

dapat menangkap jamur. RD5 merupakan primer yang mengamplifikasi spesies eukaryotik secara luas dan BhRDr merupakan primer dengan spesifisitas Blastocystis tinggi. False positive dapat terjadi, untuk itu konfirmasi melalui sekuensing dilakukan untuk mengkonfirmasi hasil tersebut positif (Stensvold et al., 2013). Sampel sebesar dua puluh delapan positif dalam pemeriksaan mikroskopis, hanya terdapat satu sampel yang terkonfirmasi mengandung Blastocystis. Terdapat beberapa kemungkinan mengenai hal tersebut diantaranya jumlah DNA
Blastocystis sp. yang tidak mencukupi untuk memunculkan band maupun primer yang kurang sensitif.

Subtyping Blastocystis dilakukan dengan 2 cara, yaitu melakukan sekuensing pada SSUrRNA (salah satumnya dengan primer barcode region) dan selanjutnya menggunakan subtipe sekuens spesifik dari tag site yang dituju (Subtipe Primer). Primer subtipe tidak memerlukan sekuensing sebagai pilihan konfirmasi namun terdapat tiga kelemahan dalam metode ini yaitu: pertama beberapa 
subtipe mungkin tidak dapat terdeteksi, hal ini dikarenakan primer subtipe hanya tersedia mulai dari ST1 hingga ST7, kedua sensitifitas yang rendah, hal ini dimungkinkan karena adanya variasi dalam intrasubtipe. Pada primer ST4, beberapa strain dari ST4 belum dapat dideteksi, hal ini dikarenakan insensitivitas dari primer tersebut, ketiga perbedaan variasi intrasubtipe tidak dapat dilakukan menggunakan metode STS. Perbandingan alel SSU-rRNA milik subtipe yang sama dapat membantu menentukan apakah suatu subtipe berbeda dengan yang lain, hal ini memiliki implikasi untuk mengidentifikasi potensi zoonosis dan apakah subtipe atau alel tertentu mendominasi dalam pengaturan gejala klinis (Stensvold et al., 2013).

Ditemukan infeksi campuran antara Blastosystis ST 1 alel 2 dan ST3 alel 34 dari sampel BK6. Infeksi campuran sangat jarang terjadi. Alfellani et al. (2013) melaporkan, infeksi campuran ditemukan sebesar 9\% (15/169) pada NHP yang diteliti. Angka yang rendah juga ditunjukkan untuk infeksi campuran pada penelitian Vaisusuk et al. (2017) pada monyet ekor panjang yaitu sebsar 4.6\%.

Subtipe 1 dan subtipe 3 merupakan subtipe yang umum ditemukan pada manusia maupun NHP di dunia (Ramírez et al., 2016). Berdasarkan penelitian yang dilakukan Sari et al. (2017) Blastocystis ST 1 dan 3 merupakan subtipe dominan yang ditemukan pada anakanak di Jakarta, Indonesia. Hasil penelitian tersebut juga sejalan dengan penelitian yang dilakukan di Thailand dan beberapa negara tetangga (Pipatsatitpong et al., 2015; Popruk et al., 2015; Palasuwan et al., 2016; Sanpool et al., 2017). Kejadian infeksi campuran pada manusia lebih tinggi dibandingkan dengan NHP (Suroiyah et al., 2018). Yoshikawa et al. (2016) melaporkan kejadian infeksi campuran antara subtipe Blastocystis pada anak di Sumba mencapai 40\% (47/118).

Infeksi campuran paling sering terjadi antara Blastocystis ST 1-3 baik pada manusia maupun NHP. Penelitian ini ST 1 alel 2 dan ST3 alel 34 ditemukan. Pada manusia alel yang telah ditemukan pada ST 1 adalah alel 1, 2, 4, 82 dan 83 serta alel 34, 36, 38, 45, 49, 55, 134 dan 128 pada ST3 (Ramírez et al., 2016). MLST telah menjadi pusat banyak penelitian yang berusaha mengungkap epidemiologi molekuler dari mikroorganisme patogen (Sullivan et al., 2005). Dengan dideteksinya Blastocystis $s p$. hingga tingkat alel diharapkan dapat membantu mengetahui epidemiologi dan patogenitas, adapun penelitian tentang hubungan alel dengan patogenitas masih dilakukan dan belum ada laporan mengenai hal tersebut. Selain itu hal ini diharapkan juga menjelaskan pola transmisi dan pertanyaan potensial mengenai kemampuan zoonosis (Stensvold, 2013).

\section{KESIMPULAN}

Monyet ekor panjang di TN Baluran, Situbondo, Jawa Timur terinfeksi Blastocystis $s p$. Prevalensi pemeriksaan mikroskopis sebesar $28 \%$ (25/90), sedangkan pemeriksaan molekuler sebesar 4\% (1/25). Monyet ekor panjang di TN Baluran terinfeksi Blastocystis Subtipe 1 alel 2 dan ST 3 alel 34. Terdapat kesamaan alel antara Blastocystis ST 1 dari monyet ekor panjang TN Baluran dengan Blastocystis ST 1 yang berasal dari manusia. Subtipe yang ditemukan merupakan subtipe yang berpotensi zoonosis.

\section{UCAPAN TERIMA KASIH}

Penulis ingin mengucapkan terima kasih kepada Kepala Taman Nasional Baluran terkait perizinan dan kepada staf Taman Nasional Baluran yang mendukung dalam pelaksanaan penelitian ini.

\section{DAFTAR PUSTAKA}

Adrus, M., Zainudin, R., Ahamad, M., Mohd-Azlan, J., Tajuddin, A.M. 2019. Gastrointestinal parasites of zoonotic importance observed in the wild, urban, and captive populations of non-human primates in Malaysia. J. Med. Primatol., 48, 22-3.

Alfellani, M.A., Jacob, A.S., Perea, N.O., Krecek, R.C., Taner-Mulla, D., Verweij, J.J., Levecke, B., Tannich, E., Clark, C.G., 
Stensvold, C.R. 2013. Diversity and distribution of Blastocystis sp. subtipes in non-human primates. Parasitol., 140(08), 966-971.

Graham, C., Stensvold. C.R. 2016. Blastocystis: Isolation, Xenic Cultivation, and Cryopreservation. Curr. Protocol Microbiol., 20A.1.1-20A.1.8.

Friishansen, M., Hariyawan, A.W., Supriyanto, S., Damanik, A.R. 2015. The interactions between long-tailed macaques (Macaca fascicularis) and tourists in Baluran National Park, Indonesia. J. Indon. Nat. History, 3, 36-41.

Palasuwan, A., Palasuwan, D., Mahittikorn, A., Chiabchalard, R., Combes, V., Popruk, S. 2016. Subtype distribution of blastocystis in communities along the chaophraya river, Thailand. Kor. J. Parasitol., 54, 455-460.

Parija, S.C., Jeremiah, S.S. 2013. Blastocystis: Taxonomy, biology and virulence. Trop. Parasitol., 3(1), 17.

Parkar, U. 2015. Molecular epidemiology of Blastocystis infections. [Thesis] Murdoch University.

Pipatsatitpong, D., Leelayoova, S., Mungthin, M., Aunpad, R., Naaglor, T., Rangsin, R. 2015. Prevalence and risk factors for blastocystis infection among children and caregivers in a child care center bangkok, Thailand. Am. J. Trop. Med. Hygiene, 93, 310-315.

Popruk, S., Udonsom, R., Koompapong, K., Mahittikorn, A., Kusolsuk, T., Ruangsittichai, J., Palasuwan, A. 2015. Subtype distribution of blastocystis in thaiMyanmar border, Thailand. Kor. J. Parasitol., 53, 13-19.

Ramírez, J.D., Flórez, C., Olivera, M., Bernal, M.C., Giraldo, J.C. 2016. Blastocystis subtyping and its association with intestinal parasites in children from different geographical regions of Colombia. PLoS ONE, 12(2).

Sari, I.P., Benung, M.R., Wahdini, S., Kurniawan, A. 2017. Diagnosis and Identification of Blastocystis Subtypes in Primary School Children in Jakarta. J. Trop. Pediatr., 64(3), 208-214.

Sanpool, O., Laymanivong, S., Thanchomnang, T., Rodpai, R., Sadaow, L., Phosuk, I., Maleewong, W., Intapan, P.M. 2017. Subtype identification of human blastocystis spp. isolated from Lao People's Democratic Republic. Acta. Tropica. 168, 37-40.

Scicluna S.M., Tawari, B., Clark, C.G. 2006. DNA Barcoding of Blastocystis. Protist, 157(1), 77-85.

Siwila, J., Isaac, G.K., Phiri, H.L.E., Mbiko, N., Olsen, A. 2011. Seasonal prevalence and incidence of Cryptosporidium spp. and Giardia duodenalis and associated diarrhoea in children attending pre-school in Kafue, Zambia, Transact. Royal Soc. Trop. Med. Hygiene, 105(2), 102-108.

Stensvold, C.R. 2013. Comparison of sequencing (barcode region) and sequence-tagged-site PCR for Blastocystis subtyping. J. Clin. Microbiol., 51(1), 190-194.

Stuart, M,D., Strier, K.B., Pierberg, S.M. 1995. A coprological survey of parasites of wild muriquis, Brachyteles arachnoides, and brown howling monkeys, Alouatta fusca. J. Helminthol. Soc Wash, 60, 111-115.

Sullivan, C.B., Diggle, M.A., Clarke, S.C. 2005. Multilocus sequence typing: Data analysis in clinical microbiology and public health. Mol. Biotechnol., 29, 245-254.

Suroiyah, F.A., Hastutiek, P., Yudhana, A., Sunarso, A., Purnama, M.T.E., Praja, R.N. 
2018. Prevalensi Infeksi Toxocara Cati pada Kucing Peliharaan di Kecamatan Banyuwangi. Jurnal Medik Veteriner, 1(3), 99-104.

Vaisusuk, K., Weerachai, S., Sutthira, S., Thongchit, T., Warayutt, P., Warong, S., Stensvold, C. R., Chairat, T. 2017. Blastocystis subtipes detected in long-tailed macaques in Thailand-Further evidence of cryptic host specificity. Acta Tropica, 184, 78-82.

Valença-Barbosa, C,T., Bergamo do Bomfim, C.B., Teixeira, R., Gentile, R., da Costa Neto, F.S., Souza, N.M., Bárbara, A.M., Alves da Silva, F., d'Avila Levy, B.R.M., Santos, C.C., Helena, L. 2019. Molecular epidemiology of Blastocystis isolated from animals in the state of Rio de Janeiro, Brazil. PLOS ONE.

Yoshikawa, H, Wu, Z., Pandey, K., Pandey, B.D., Sherchand, J.B., Yanagi, T., Kanbara. H. 2009. Molecular characterization of Blastocystis isolates from children and rhesus monkeys in Kathmandu, Nepal. Vet. Parasitol., 160(3-4), 295-300.

Yoshikawa, H, Tokoro, M., Nagamoto, T., Arayama, S., Asih, P.B., Rozi, I.E., Syafruddin, D. 2016. Molecular survey of Blastocystis sp. from humans and associated animals in an Indonesian community with poor hygiene. Parasitol. Int., 65, 780-784.

Zanzani, S.A., Gazzonis, A.L., Epis, S., Manfredi, M.T. 2016. Study of the gastrointestinal parasitic fauna of captive non-human primates (Macaca fascicularis). Parasitol., 115, 307-312.

Zhang, X., Qiao, J.Y., Zhou, X.J., Yao, F.R., Wei, Z.N. 2012. Morphology and reproductive mode of Blastocystis hominis in diarhea and in vitro. Parasitol. Res., 101, 43-51. 